\title{
A LITERATURA COMPARADA NO BRASIL
}

\author{
Gilda Neves da Silva Bittencourt
}

\begin{abstract}
RESUMO: Comparatism followed the steps of Brazilian literature investigation even before the establishment of Comparative Literature as a sistematic study, for it was a spontaneous practice which was present in the critical essays by different scholars. Comparative Literature has been introduced in Brazilian University from the 30's onwards. The name of Antonio Candido de Mello e Souza has contributed to its development and consolidation, mainly through his renewed ideas of the concept of influence. His critical discourse was the starting point for the search of a decolonized comparativist model. The establishment of graduate courses in Comparative Literature on a regular basis has given a great impetus to the field in Brazil, producing in-depth studies which have shown the interliterary relations through a new point of view, breaking with the tradicional concepts of debts and influences. The ripening of Comparative Literature in Brazil can be measured by the creation of the National Association (ABRALIC) in 1986, and by the realization of four National Conferences.
\end{abstract}

PALAVRAS-CHAVE: literatura comparada, história do comparatismo no Brasil, conceito de influência, modelo comparatista descolonizado.

Os estudos de Literatura Comparada no Brasil não podem ser desvinculados dos estudos da própria Literatura Brasileira, ou, mais especificamente, da atividade crítica desenvolvida sobre ela desde o Romantismo. Esta constatação encontra respaldo nas palavras do professor e crítico literário Antonio Candido de Mello e Souza, quando afirma que

\footnotetext{
"a nossa produção foi sempre tão vinculada aos exemplos externos, que insensivelmente os estudiosos efetuavam as suas análises ou elaboravam os seus juízos tomando a esses como ponto de reparo." (MELLO E SOUZA, 1988, p. 17)
}

Universidade Federal do Rio Grande do Sul 
Assim, muito antes de se instituir entre nós a noção de Literatura Comparada como abordagem literária e estudo sistemático, historiadores e exegetas da literatura brasileira, ainda no século XIX, já a praticavam espontaneamente. Esse é o caso de Tobias Barreto, um apaixonado pela literatura e a cultura alemãs que, além de abrir um curso de Literatura Comparada em 1886 no Recife, publicou em jornais vários ensaios críticos, os quais tencionava reunir num livro intitulado Traços de Literatura Comparada do Século XIX. Infelizmente, o crítico sergipano não chegou a concretizar o seu intento, mas graças ao esforço de Sílvio Romero, seu amigo e testamenteiro literário, o trabalho inacabado foi incluído na segunda edição dos Estudos Alemães de Tobias, lançado em 1892, dois anos após a sua morte.

A fonte dos estudos de Tobias, como não poderia deixar de ser no século XIX, vinha da Europa, do crítico dinamarquês Georg Brandes, que o pensador brasileiro leu na sua tradução alemã. Brandes, seguindo a mesma linha dos comparatistas europeus da época, considerava somente as grandes obras como objetos de análises comparatistas. Com base nessa idéia de Brandes, Tobias considerava que a "Literatura Comparada só podia existir nas nações cultas, pois somente elas tinham obras capazes de resistir ao confronto severo dos intercâmbios culturais" (FARIA, 1991, p. 27). Assim, elegeu a literatura alemã como o centro de suas operações, demonstrando a sua superioridade sobre as demais, revelando, nesse juízo valorativo que pressupõe uma forte dependência cultural, as mesmas distorções encontradas nos comparatistas europeus do século XIX.

Se em Tobias Barreto há uma intenção manifesta de fazer comparatismo, em outros críticos brasileiros do século passado isso fica implícito na metodologia de análise adotada, que era invariavelmente a de fazer referências a obras e autores estrangeiros

$$
\begin{aligned}
& \text { "como se a capacidade do brasileiro ficasse justificada pela } \\
& \text { afinidade tranqüilizadora com os autores europeus, participantes } \\
& \text { de literaturas antigas e ilustres, que, além de influírem na nossa, } \\
& \text { vinham deste modo dar-lhe um sentimento confortante de } \\
& \text { parentesco." (MELLO E SOUZA, 1988, p. 17) }
\end{aligned}
$$

Essa busca de uma filiação segura, capaz de confirmar o status literário dos nossos autores, era igualmente uma manifestação de uma ótica dependente que buscava sempre o referencial europeu como parâmetro de avaliação.

Nos inícios do século XX, os estudos comparatistas dispersos nas obras de críticos brasileiros adquirem uma feição ligeiramente diferenciada, no que tange às orientações da chamada Escola Francesa. O nome de João Ribeiro é cronologicamente o primeiro a deslocar essa perspectiva tradicional, ao encarar a literatura comparada como uma atividade de crítica histórica, e ao pensar a produção cultural nas suas relações entre o estrato 
culto (a literatura erudita) e o estrato espontâneo (a literatura popular), sobretudo no ensaio Literatura Comparada, incluído em Páginas de Estética (1905), evidenciando uma postura precursora das teses defendidas anos mais tarde por René Wellek e Austin Warren em sua Teoria da Literatura (1949) (Cf. CARVALHAL, 1986, p. 23).

Mais adiante, críticos como Otto Maria Carpeaux, Eugênio Gomes e Augusto Meyer desenvolveram trabalhos onde o comparatismo ressalta como uma prática quase inevitável, como se os próprios textos os conduzissem a isso. O primeiro caracterizou-se sempre pela postura comparatista, evidenciada por uma visão crítica onde ressaltam a inclinação ao confronto e à inserção de cada obra no conjunto das produções textuais. Faziam parte de seu projeto intelectual a universalização do conhecimento e a totalização de fenômenos através de seu inter-relacionamento, razão pela qual Otto Carpeaux buscava invariavelmente, nos textos analisados, parentescos, afinidades, elementos comuns e convenções. A chave encontrada para estabelecer tais relações no processo de transformação literária foi a análise estilístico-sociológica, que pode ser identificada em especial na sua História da Literatura Ocidental (1959), mas que se faz presente em inúmeros outros ensaios que compõem sua vasta obra crítica. Em estudo sobre a obra de Carpeaux, a prof ${ }^{\mathrm{a}}$. Tania Carvalhal reconhece, na atividade do crítico austríaco naturalizado brasileiro, uma função considerada decisiva nos estudos comparatistas: a do intermediário. Através de sua atuação contínua na imprensa e nas várias publicações, "revelou ao leitor brasileiro inúmeros autores europeus aqui desconhecidos" (CARVALHAL, 1990, p. 92), estabelecendo vínculos entre a nossa literatura e as literaturas estrangeiras.

Eugênio Gomes rastreou as fontes da obra de Machado de Assis, em busca de suas influências inglesas. Nesse trabalho, identifica tanto os termos de contato, de coincidência com autores ingleses, mas aponta também as modificações e adaptações introduzidas pelo autor brasileiro, refutando assim as acusações de mera imitação às obras de Swift e Sterne, feitas à obra de Machado, sobretudo por Sílvio Romero.

Augusto Meyer dedicou-se à pesquisa das fontes, sob a inspiração do trabalho realizado por Ernst Robert Curtius em Literatura Européia e Idade Média Latina (1948), cuja tradução fora editada pelo Instituto Nacional do Livro por iniciativa do próprio Meyer. O crítico gaúcho, porém, relativiza a importância de tal metodologia, pois, para ele, o mais importante não era mostrar a filiação passiva, ou a coincidência com um determinado modelo, mas sobretudo destacar as divergências, as ultrapassagens criativas, através de uma profunda análise estilística das obras. O que ressalta na visão crítica de Meyer é, sobretudo,

"a justeza da desconfiança que demonstra em relação às pesquisas de influências e, principalmente, como se retrai diante dos paralelismos binários sem caráter interpretativo tão freqüentes 
nos estudos tradicionais de crenologia" (CARVALHAL, 1986, p. 27).

O que se vê, portanto, na história do comparatismo no Brasil, é uma prática difusa e espontânea a percorrer os ensaios críticos muito antes do surgimento da Literatura Comparada como um determinado ramo dos estudos literários, fixado por princípios teóricos específicos, ou mesmo de sua institucionalização como disciplina acadêmica.

A introdução da Literatura Comparada na Universidade brasileira se deu ainda na década de 30, com a fundação da Faculdade Paulista de Letras e Filosofia, que previa uma disciplina de História Comparada das Literaturas Novo-Latinas. Nos anos 40, aparece pela primeira vez a cadeira de Literatura Comparada, ministrada por Tasso Silveira na Faculdade de Filosofia do Instituto Lafayette (depois Faculdade de Filosofia e Letras do Estado da Guanabara). Tasso é autor do primeiro manual de Literatura Comparada editado no Brasil (1964), onde condensou os ensinamentos que realizou como docente, revelando igualmente a sua perfeita adesão aos princípios do francês Van Tieghen, expressos na obra de 1931 - La Littérature Comparée. Assim sendo, o manual de Tasso Silveira assimilou inteiramente as orientações dos mestres franceses,

"cuja receita era pesquisar influências, buscar identidades ou diferenças, restringindo o alcance da literatura comparada ao terreno das aproximações binárias e à constituição de famílias literárias." (CARVALHAL, 1986, p. 20)

Ainda no âmbito universitário, data de 1945 o aparecimento da primeira tese em Literatura Comparada, realizada por Antônio de Salles Campos, que estudou as origens e a evolução dos temas da primeira geração de poetas românticos brasileiros. Nos anos 50, o conhecido professor Fidelino de Figueiredo orientou uma tese sobre temas ingleses na literatura portuguesa e publicou, na Revista da Universidade de São Paulo, um ensaio sobre Shakespeare e Garrett. ( Cf. NITRINI, 1986, p. 42)

No quadro da Literatura Comparada brasileira, tanto na sua vertente acadêmica, como na prática crítica, merece destaque o nome de Antonio Candido de Mello e Souza. Candido foi o introdutor da disciplina na Universidade de São Paulo e o criador do setor de Teoria da Literatura e Literatura Comparada, em 1962, tendo ministrado inúmeros cursos e orientado dissertações de mestrado e teses de doutorado em Literatura Comparada. Por outro lado, em sua atividade crítica e ensaística, Candido também revela uma forte inclinação comparatista, manifesta desde os seus primeiros escritos, mas explicitada quando da realização de seu conhecido trabalho de história literária, em Formação da Literatura Brasileira Momentos Decisivos - (1957). Ao definir o conceito de influência, o autor ressalta a sua importância, por considerá-lo o instrumento "mais delicado, falível e perigoso de toda crítica, pela dificuldade em distinguir coincidência, 
influência e plágio" (MELLO E SOUZA, 1975, p. 37). O problema atinge proporções mais significativas, segundo Candido, quando a influência assume sentidos variáveis, exigindo um tratamento também diverso, já que ela pode aparecer "como transposição direta, mal assimilada, permanecendo na obra ao modo de um corpo estranho de interesse crítico secundário" (MELLO E SOUZA, 1975, p. 38), mas pode igualmente adquirir um significado orgânico, perdendo o caráter de empréstimo, já que é assimilada como elemento próprio, constituinte de um novo conjunto íntegro. O que preocupa o crítico Antonio Candido são sobretudo os modos de absorção, de transformação e de afastamento dos modelos europeus, preocupações que se fazem presentes em inúmeros trabalhos disseminados em sua extensa obra, caracterizando assim "uma atitude comparatista intimamente ligada com o Brasil e que encontra, por isso, uma maneira peculiar e nossa de examinar a questão" (CARVALHAL, 1988, p. 15).

Seu conhecimento profundo da literatura brasileira e sua intenção de explicar o seu funcionamento como sistema articulado levou-o a formular a dialética do localismo e do cosmopolitismo, espécie de lei de evolução da nossa vida espiritual. Tal dialética se manifesta, segundo Candido, de modos diversos:

"ora a afirmação premeditada e por vezes violenta do nacionalismo literário, com veleidades de criar até uma língua diversa; ora o declarado conformismo, a imitação consciente dos padrões europeus" (MELLO E SOUZA, 1976, p. 109).

Nesse processo, em que se integram experiência literária e espiritual, manifesta-se uma tensão permanente entre o dado local ( a substância da expressão) e os modelos herdados da tradição européia ( a forma da expressão).

Assim, tanto a nossa produção literária como a atividade crítica manifestaram sistematicamente essa postura dialética de apreensão do real. Tal atitude, identificada e definida por Antonio Candido, tem orientado boa parte dos trabalhos comparatistas desenvolvidos no Brasil. Desse modo,

"sua obra ilustra exemplarmente uma forma legítima de
comparatismo no Brasil: a do esforço empenhado na análise dos
processos de transformação da colaboração européia, examinando
como o individual se cruza com o coletivo, para que se possa
perceber o que é peculiar à literatura aqui produzida, na expressão
de seu vínculo com o país e a cultura através da qual ele se faz
presente no mundo" (CARVALHAL, 1988, p. 16)

Assim, o seu discurso crítico pode se constituir num importante ponto de partida para a busca de um modelo comparatista descolonizado, justamente por se propor a analisar os mecanismos através dos quais uma 
literatura responde criativamente aos impactos recebidos de fora (Cf. NITRINI, 1986, p.44).

Além de pensar as relações interliterárias Brasil/Europa, Candido também tem se preocupado com a inserção da literatura brasileira no contexto latino-americano, fato que constitui uma importante vertente do comparativismo aqui praticado. Para o crítico, a natureza dessa relações transcende o meramente literário por incluir motivações também de ordem político-ideológica, pois antes de tudo é preciso buscar uma união entre as nações para nos fortalecer como um conjunto onde coexistam idéias harmônicas e contrastantes. E,

\begin{abstract}
"ao sugerir que a busca das diferenças é tão essencial quanto a das semelhanças, salienta que importa pensar as relações em termos de América Latina com a finalidade de criar outras categorias de mediações, que nos possibilitem o encontro, não fora, mas dentro de nosso próprio território" (CARVALHAL, 1988, p.16)
\end{abstract}

Fica superada, dessa forma, uma visão colonizada, orientada pelas dicotomias centro/periferia, colonizador/colonizado, substituída por uma situação de equilíbrio interno.

No final dos anos 60 e início dos 70, houve um importante impulso nos estudos de Literatura Comparada no Brasil com a introdução dos cursos regulares de pós-graduação, determinando uma produção mais sistemática de trabalhos de maior fôlego. Caracteriza essa fase sobretudo a ausência de uma bibliografia teórica consistente em língua portuguesa, já que as obras disponíveis eram a tradução de La littératura Comparée, de Guyard, e o manual Literatura Comparada, de Tasso Silveira, que, como vimos anteriormente, seguia estritamente os princípios de Van Tieghen.

Entre os trabalhos desenvolvidos nessa época, alguns se destacam pelo registro de transformações e diferenças no confronto da literatura brasileira com a européia, sobretudo por contrariarem uma noção tradicional de influência, oriunda do comparativismo francês, encarada como débito, filiação, dentro de uma perspectiva etnocêntrica que privilegia a obra primeira e que considera somente a direção unilateral no sentido do original à copia, ou do influenciador ao influenciado. Em estudo sobre a história da Literatura Comparada no Brasil, a prof ${ }^{\mathrm{a}}$. Sandra Nitrini, da USP, aponta dois trabalhos apresentados como teses de doutoramento, onde esses aspectos se fazem presentes. O primeiro, Byron no Brasil, Traduções, de Onédia Barbosa (1969), estuda a voga do byronismo no romantismo brasileiro; o segundo, Astarte e a Espiral, de Maria Alice Faria (1970), analisa a presença de Musset em Álvares de Azevedo. No primeiro, a autora consegue mostrar que o byronismo estava mais na imaginação dos tradutores do que no texto original, caracterizando uma verdadeira aclimatação de Byron no Brasil, já que, nas suas várias traduções brasileiras, "o poeta inglês sofre uma completa metamorfose que se processa sob a ação do classicismo, romantismo, simbolismo e realismo brasileiros" (NITRINI, 1991, p.214). No segundo, a 
autora tenta, sem êxito, utilizar como suporte teórico o conceito de influência tradicional (escola francesa), vindo a constatar, em sua análise contrastiva dos textos do poeta brasileiro e do francês, que eles mostravam mais as diferenças do que as semelhanças. Este fato levou-a a mudar a orientação antes adotada e optar pelo conceito de afinidade que se mostrou mais operatório, sobretudo porque dizia respeito às biografias e aos temperamentos dos dois poetas, referindo-se, portanto, a um espaço exterior às obras poéticas. Segundo Sandra Nitrini, o trabalho ficaria bastante comprometido se não fosse por um outro elemento ali presente: uma análise da tradução-interpretação do poema Rolla, de Musset, feita por Álvares de Azevedo. Nela, a autora de Astarte e a Espiral consegue mostrar que o poeta brasileiro "teria lido Musset pelas lentes deformadoras da corrente byroniana no Brasil" (NITRINI, 1991, p. 216). Assim, o trabalho adquire uma dupla importância para o estudo da questão da influência no comparativismo brasileiro: 1) mostra que essa questão ultrapassa o mero cotejo binário, pois inclui aspectos mais amplos referentes a correntes, modas e vogas européias e locais; 2) torna evidente a verdadeira poética de deformação realizada por Álvares de Azevedo na tradução de Musset.

Desta forma, ao privilegiar a transformação, a autora

\begin{abstract}
"está pontuando, no seu discurso crítico, o pólo diferencial do conceito de influência, e por conseguinte, pelo menos nessa parte, Astarte $e$ a Espiral escapa da visão tradicional da literatura comparada, vindo a se integrar, juntamente com Byron no Brasil, na linha do comparativismo universitário inaugurada por Antonio Candido" (NITRINI, 1991, p.217)
\end{abstract}

que, como vimos antes, prevê para influência um novo significado que implica deformação e adaptação às necessidades do objeto analisado.

Ainda nos anos 70, se consolidou, na Universidade de São Paulo, o projeto Léryy-Asuu, dirigido pela professora Leyla Perrone-Moisés junto às disciplinas de Língua e Literatura Francesas da Faculdade de Filosofia, Letras e Ciências Humanas, tendo por objetivo o estudo das marcas francesas na literatura brasileira, citando apenas uma de suas áreas de interesse nos estudos comparatistas. As inúmeras teses resultantes desse projeto demonstram o delineamento de novas linhas de pesquisa e o enriquecimento da produção intelectual brasileira na área dos estudos comparatistas.

O crescimento da Literatura Comparada e a sua progressiva institucionalização levaram à realização, em Porto Alegre, RS, do I Seminário Latino-Americano de Literatura Comparada (1986), ocasião em que foi criada a Associação Brasileira de Literatura Comparada, tendo como sua primeira presidente a Prof ${ }^{\mathrm{a}}$. Tania Franco Carvalhal, da UFRGS. O nascimento da instituição deu-se num momento em que já se havia consolidado uma reflexão própria sobre as relações interliterárias e em que já havia uma massa crítica consistente, capaz de formular de forma madura a natureza dos processos de transformação e de assimilação por que passou a 
literatura brasileira no seu confronto com as estrangeiras. Justamente pelo conhecimento desse processo e da reflexão dele resultante, já havia condições de se adotar uma postura conciliadora entre uma visão tradicional que implicava dependência cultural, e uma atitude nacionalista e chauvinista que negava radicalmente as premissas anteriores, advindas do comparatismo francês, sobretudo. Essa foi a forma encontrada para se configurar uma reflexão autenticamente brasileira de Literatura Comparada, que se vincula igualmente a um modo latino-americano de pensar as relações interliterárias, e que se faz presente nos inúmeros projetos que vêm se desenvolvendo a partir de então.

Desde o seu surgimento, a ABRALIC já efetivou quatro congressos nacionais: Porto Alegre, 1988, Belo Horizonte, 1990, Niterói, 1992, São Paulo, 1994. Todos eles contaram invariavelmente com a participação de analistas estrangeiros de grande renome e com um número cada vez maior de pesquisadores brasileiros, demonstrando com isso a pujança dos trabalhos aqui desenvolvidos e o interesse crescente da Literatura Comparada nos meios acadêmicos.

\section{BIBLIOGRAFIA}

CARVAlHAL, Tania Franco. Literatura comparada. São Paulo, Ática, 1986. Série Princípios.

- Antonio Candido e a literatura comparada no Brasil. Anais do I Congresso ABRALIC. Porto Alegre, UFRGS, p. 13-16, 1988.

- A intermediação da memória: Otto Maria Carpeaux. Anais do II Congresso ABRALIC. Belo Horizonte, UFMG, v. 1, p. 85-95, 1990.

FARIA, Gentil Gomes de. Tobias Barreto e a literatura comparada. Anais do II Congresso ABRALIC. Belo Horizonte, UFMG, v. 1, p. 22-29, 1991.

MELLO E SOUZA, Antonio Candido. Formação da literatura brasileira (momentos decisivos). 5. ed. Belo Horizonte, Itatiaia, São Paulo/EDUSP, Vol. 1, 1975.

MELLO E SOUZA, Antonio Candido. Literatura e cultura de 1900 a 1945. In: Literatura e sociedade. 5. ed. Editora Nacional, 1976.

. Palavras do homenageado. Anais do I Congresso ABRALIC. Porto Alegre, UFRGS, p. 17-20, 1988.

NITRINI, Sandra. Em torno da literatura comparada. BOLETIM BIBLIOGRÁFICO. São Paulo, Biblioteca Mário de Andrade, v. 47, n. 1/4, jan/dez 1986.

. Literatura Comparada no Brasil - um fragmento de sua história. Anais do II Congresso ABRALIC. Belo Horizonte, UFMG, v. 1, p. 211-218, 1991. 
